O PROJETO DE EXTENSÃO "FALANDO EM FAMÍLIA" COMO VETOR DE ACESSO À JUSTIÇA E EXERCÍCIO PLENO DE CIDADANIA

Por Zilda Mara Consalter Dirce do Nascimento Pereira

BOAS PRÁTICAS 


\title{
O PROJETO DE EXTENSÃO "FALANDO EM FAMÍLIA" COMO VETOR DE ACESSO À JUSTIÇA E EXERCÍCIO PLENO DE CIDADANIA
}

\author{
THE EXTENSION PROJECT "TALKING IN FAMILY” AS A VECTOR FOR ACCESS TO JUSTICE \\ AND FULL EXERCISE OF CITIZENSHIP
}

Por Zilda Mara Consalter

Doutora em Direito Civil pela Universidade de São Paulo, Brasil.

zilda_advocacia@hotmail.com

Por Dirce do Nascimento Pereira

Doutoranda em Direito Econômico e Socioambiental na Pontifícia Universidade Católica do

Paraná, Brasil.

dircenpereira@hotmail.com

\section{INTRODUÇÁO}

$\mathrm{O}$ acesso à justiça é direito constitucionalmente assegurado no artigo $5^{\circ}$, inciso XXXV da Constituição (1988) e figura entre os direitos fundamentais conferidos à pessoa. Contudo, para ser exercido em sua plenitude, impera que o processo judicial tenha celeridade e seja capaz de solucionar o conflito havido entre as partes em tempo e condições razoáveis.

Diante dessa constatação, é inevitável a busca por uma nova forma de lidar com a resolução de demandas, sendo que as vias da conciliação e mediaçáo despontam como boas alternativas a serem seguidas sendo, inclusive, incisivamente estimuladas pela legislação mais recentes.

Somente a título de ilustração, a base principiológica do novo Código de Processo Civil (CPC) se assenta sob os princípios da conciliação e mediação, buscando estabelecer o diálogo e o entendimento entre as partes e fazendo-se dever de todos - juízes, advogados, 
defensores públicos e integrantes do Ministério Público, estimular a resolução pacífica dos conflitos, conforme estabelecido no seu artigo $3^{\circ}$.

Somado ao aporte normativo, tem-se que dos milhares de processos que tramitam nos tribunais brasileiros, boa parcela corresponde a açôes afetas ao Direito das Famílias e que, nessa área, despontam com um diferencial: a íntima relação com os sentimentos das partes e o envolvimento de vulneráveis, que nem sempre são partes nos feitos, mas que se mostram como diretamente afetados. Essas peculiaridades fazem com que, na maioria das vezes, as ações perdurem por muito tempo, causando grande sofrimento e desgaste aos envolvidos.

Com base nisso, verifica-se a necessidade de uma abordagem diferenciada para com os jurisdicionados, permitindo-lhes conhecer novas alternativas para a solução de seus conflitos - além da sentença - que lhes garanta de modo efetivo o acesso à justiça. Daí surgiu o Projeto de extensão "Falando em família" como uma prática institucional voltada ao exercício pleno da cidadania.

\section{DESCRIÇÃO DA PRÁTICA INSTITUCIONAL}

Em atenção ao panorama acima delineado, o Projeto de Extensão "Falando em Família" é resultante da parceria entre a Universidade Estadual de Ponta Grossa (Departamento de Direito das Relaçóes Sociais), Faculdade Secal e Tribunal de Justiça do Estado do Paraná, por intermédio do Centro Judiciário de Solução de Conflitos e Cidadania de Ponta Grossa-Pr (CEJUSC/PG). Referido Projeto conta com a participação de 10 docentes e mais de 60 discentes, todos ligados aos Cursos de Bacharelado em Direito das duas Instituiçóes de Ensino envolvidas, além de servidores do Poder Judiciário e bacharéis voluntários.

Seu lançamento ocorreu no dia 15 de maio de 2015 - Dia Internacional da Família - em cerimônia que contou com a palestra do Ministro do Superior Tribunal de Justiça (STJ), Marco Aurélio Gastaldi Buzzi, Conselheiro Honorífico da Escola Nacional de Mediação e Conciliação e atuante junto ao Movimento Nacional pela Conciliação, vinculado ao Conselho Nacional de Justiça (CNJ). Na ocasião, o Ministro destacou o valor de iniciativas como esta, que vão ao encontro da recomendação contida na Resolução n.o 125/2010 do CNJ e também da política dos CEJUSCs, que tem a função de impulsionar a utilizaçáo 
de métodos de resolução adequada de conflitos como a conciliação, a mediação e a justiça restaurativa, além de incentivar a participação ativa de todos os atores envolvidos no litígio, fazendo com que sejam protagonistas na busca do consenso e não meros expectadores de uma decisão verticalizada.

Em razão de seus objetivos e da importância das atividades desenvolvidas, o Projeto recebe o apoio da Magistratura e do Ministério Público Estaduais, dos Núcleos de Prática Jurídica, da Ordem dos Advogados do Brasil (Subsecção de Ponta Grossa) e da Defensoria Pública do Estado do Paraná da mesma Comarca.

\section{PÚBLICO ALVO E OBJETIVO GERAL}

A disseminaçấo da cultura da adoção de práticas adequadas na resolução de conflitos (composição amigável) aos jurisdicionados das Varas de Família da Comarca de Ponta Grossa, Estado do Paraná, que forem parte ativa, passiva ou interessada em processos que contenham demandas com vulneráveis envolvidos é a maior finalidade do Projeto. Para tanto, ele finca-se no tripé "informar $=>$ ouvir $=>$ sensibilizar" para intentar o seu mote.

\section{CENÁRIO DE ATUAÇÃo}

As açôes de alimentos e divórcio abrangem espécies de açôes do Direito das Famílias, o que, inexoravelmente, atinge as partes, e especialmente os vulneráveis (crianças e adolescentes), que ficam em situação de fragilidade emocional e psicológica. E, em razão dessa circunstância especial, os processos judiciais em trâmite nessa esfera são, via de regra, bastante desgastantes e delongados, causando diversas consequências às partes e demais interessados. Pela demora natural do tramitar, ocorre um acúmulo de açóes nas Varas de Família das Comarcas brasileiras, em que a efetividade esperada sofre diversos percalços.

Por seu turno, a desordem emocional impede a aceitação da sentença e, muitas vezes, não cabe nos estreitos limites do processo, resolver as inúmeras questóes que envolvem o conflito que se instala no relacionamento dos ex-parceiros. Nessas condiçóes, em muitas situaçôes os filhos ficam expostos a toda a situação de prejuízo, o que contraria o princípio do melhor interesse e proteção integral erigidos pelo Estatuto da Criança e do Adolescente. 
Todos esses fatores fazem com que o processo judicial se torne ainda mais lento e uma verdadeira fonte de sofrimento para todos os envolvidos.

Assim, e em atenção a esse cenário, o $\mathrm{CNJ}$ orienta que se tente buscar métodos alternativos de resolução de conflitos, a fim de evitar o litígio utilizando-se das ferramentas jurídicas hábeis e possíveis para tanto.

\section{METODOLOGIA E APORTE TEÓRICO}

A realizaçáo do Projeto ocorre por meio de encontros, corriqueiramente chamados de oficinas, entre os seus membros e os jurisdicionados e tem por finalidade preparar as partes em processos das Varas de Família da Comarca de Ponta Grossa para a audiência de conciliação.

Durante essas reuniôes, sempre que possível, é destacado o alcance de uma sentença homologatória de acordo, bem como o abrandamento das mágoas e principalmente a preservação dos interesses dos vulneráveis envolvidos no conflito. Nelas éfeito o acolhimento da parte e dada a ela a oportunidade de ser ouvida quanto aos questionamentos e relatos, bem como a sensibilizaçáo e fornecimento de informaçôes as partes sobre as questôes atinentes ao Direito das Famílias, sempre demonstrando interesse pelas manifestações e principalmente, o respeito ao silêncio de cada jurisdicionado.

Cada oficina é programada para durar, em média, de uma hora e meia a duas horas, e pode contar com a participaçáo de até 30 jurisdicionados, ocorrendo uma vez por semana na sede do CEJUSC/PG, sendo que as partes de um mesmo processo participam de sessões separadas, como forma de evitar polemizações, confrontos e de propiciar a reflexão de cada polo de modo separado: dessa maneira eles têm a oportunidade de conversar mais a vontade com os membros do Projeto.

Embora a equipe do Projeto seja formada por cerca de 40 acadêmicos e 10 professores (provenientes das duas Instituições de Ensino), as oficinas são conduzidas - e as informaçôes prestadas - por grupos que se revezam semanalmente, formados por 8 acadêmicos e 2 professores coordenadores.

Quanto a esse ponto importa ressaltar que cada integrante da equipe passou por prévia 
capacitação técnica, com estudos direcionados para questóes de Direito Processual Civil, de Direito das Famílias e princípios da Mediaçâo e Conciliação. ${ }^{12}$ Além do estudo do direito material e adjetivo, ainda são apresentadas algumas técnicas de conciliação, pela explicação de um estudo de caso, sendo também disponibilizado ao grupo de alunos material referente à Resolução n ${ }^{\circ} 125$ de 29 de novembro de 2010, do Conselho Nacional de Justiça, que dispóe sobre a política judiciária nacional de tratamento adequado dos conflitos no âmbito do Pode Judiciário. ${ }^{3}$

Ao participar dos encontros, os jurisdicionados são convidados a se sentar na forma de um semicírculo, em que todos se apresentam e tem a oportunidade de falar a respeito de suas açôes e sanarem dúvidas sobre questôes processuais e materiais. Em seguida, são aplicadas dinâmicas e jogos cooperativos a fim de conscientizar quanto à necessidade de eliminação do cenário da disputa e do confronto para evidenciar a importância de valores como a cooperação e o respeito mútuo. ${ }^{4}$ Ainda quanto a parte lúdica, são utilizadas dinâmicas e vídeos que tem por objetivo a reflexão e o incentivo a conciliação. É feita alusão (jamais a sugestão) aos acordos, a fim de estimulá-los a solucionar suas pendências com a outra parte de forma que traga o menor prejuízo para os vulneráveis envolvidos nestas relaçóes e assim manter a relação parental.

Esta postura foi pensada face à Lei $\mathrm{n}^{\circ}$. 13.105/15, (CPC) já que, desta forma, a autocomposição deixa de ser apenas um método extrajudicial de solução de conflitos, mas ganhando contornos mais definidos:

É a forma de solução do conflito pelo consentimento espontâneo de um dos contendores em sacrificar o interesse próprio, no todo ou em parte, em favor do interesse alheio. É a soluçâo altruísta do litígio. Considerada, atualmente, como legítimo meio alternativo de pacificação social. Avança-se no sentido de acabar com o dogma da exclusividade estatal para a soluçáo dos conflitos de interesses. Pode ocorrer fora ou dentro do processo jurisdicional. ${ }^{5}$

Por outro prisma, a importância da resoluçáo pacífica do conflito mediante conciliação não está

\footnotetext{
1 SCALQUETTE, A. C. S. Família e sucessóes, 2014.

2 VILLAÇA AZEVEDO, A. Direito de família, 2013.

3 CONSELHO NACIONAL DE JUSTIÇA. Justiça em números: publicado em janeiro de 2014. Disponível em: ftp://ftp.cnj.jus.br/Justica_em_Numeros/relatorio_jn2014.pdf. Acesso em: 27 abr 2016.

4 CORREIA, M. M. Trabalhando com jogos cooperativos, 2012.

5 DIDIER JR, F.; Curso de direito processual civil: introdução ao direito processual civil, parte geral e processo de conhecimento I, 2015.
} 
apenas na preservação dos laços afetivos, mas também, na questão da celeridade do processo, já que a autocomposição exclui a necessidade de continuar com a lide judicial, resolvendo-se, dessa forma, definitivamente a questão.

O resultado esperado das audiências é a realização do acordo, que será reduzido a termo (escrito), constando minuciosamente todos os pontos pactuados entre as partes e terá natureza jurídica de título executivo judicial, em razão da sua homologação por sentença pelo juiz competente, obedecido do disposto no art. 515, II, do NCPC, facilitando a satisfação do acordo face a uma possível inadimplência de um dos acordantes. [...] É mais do que sabido que o Novo Código de Processo Civil foi projetado visando propiciar uma maior celeridade aos processos, sejam os novos ou os já em curso, posto que a regra processual tem aplicação imediata aos processos pendentes. Como um instrumento, isto é, ferramenta utilizada para se chegar a este resultado, figura a promoçáo veemente da autocomposição, o que é fato. ${ }^{6}$

No que tange aos estímulos aos meios consensuais de solução de conflito, tem-se que:

O novo Código estimula os mecanismos alternativos (rectius adequados) de soluçáo de conflitos e, em uma dessas perspectivas, a regra geral passa a ser a de que, ajuizada uma ação, não sendo o caso de indeferimento da inicial ou improcedência liminar do pedido, o réu será citado, com uma antecedência de pelo menos vinte dias, não para contestar, mas para comparecer à audiência de conciliaçấo ou de mediação. Essa audiência poderá ser realizada também por meios eletrônicos.

Ainda deve-se observar que nessas reuniōes, a aplicação do Direito das Famílias quando as dúvidas trazidas pelos jurisdicionados são sanadas ocorre de forma a promover a função social da família, que,

[...] é verificada como reflexo da própria evolução da sociedade, revelando-se claro o redirecionamento das relaçôes familiares no sentido de preservar o que há de mais importante nas famílias: o sentimento afetivo, a solidariedade. A proteçấo mútua, o respeito, a consideração ${ }^{8}$.

Cientes de tudo isso, e uma vez terminadas as atividades da oficina, é solicitado que os

6 GOULART, L. H. S.; PINTO, B. S. M. A autocomposição sob a óptica do novo código de processo civil: o encaixe da mediação e da conciliação na nova sistemática processual. Revista Pós em Revista, ediçáo 10, 25 de maio de 2015. Disponível em: < http://blog.newtonpaiva.br/pos/e10-dir02-aautocomposicaosob-a-optica-do-novo-codigo-de-processo-civil-o-encaixe-da-mediacao-e-daconciliacao-na-nova-sistematicaprocessual/> Acesso em: 01 jun. 2016.

7 ARRUDA ALVIM WAMBIER, T.; MENDES, A. G. de C. O novo código de processo civil brasileiro. Quarta, 16 de setembro de 2016. Dsponível em: <http://teste.wambier.com.br/ptbr/artigos-br/onovo-codigo-de-processo-civil-brasileiro> Acesso em: 01 jun. 2016.

8 GAMA, G. C. N.; GUERRA, L. dos S. Função social da família. In: GAMA, G. C. N. Função social no direito civil, 2008. 
participantes preencham um formulário avaliando as atividades desenvolvidas. Com isso, é possível aferir a evolução do Projeto e as mudanças necessárias para maior aproveitamento da comunidade.

Em pouco tempo de Projeto foi possível observar, pela análise dos questionários, que os resultados têm sido positivos. As partes saem das oficinas mais propensas ao diálogo e conscientizadas da importância da solução pacífica de dissensos, preservando, em ultima ratio, os vulneráveis, que são, em regra, os mais afetados nesses conflitos.

Finalmente, é de se ressaltar que a participação das partes, apesar de não ser obrigatória, não retira a importância do comparecimento de todos os convidados, na medida em que poderão manifestar seu problema, ouvir experiências de outras pessoas que estejam passando por situação semelhante e receber orientaçóes sobre aspectos relativos ao direito de família. Nesta oportunidade, a presença dos advogados/defensores éfacultativa, mas a parceira dos causídicos é de suma importância para o incentivo e a orientaçáo aos jurisdicionados, a fim de que participemdasoficinasecompreendamarelevânciadoprojetocomoformadepacificaçáosocial.

\section{ALGUNS NÚMEROS}

Dentre as inúmeras justificativas para a existência de tal Projeto, pode-se mencionar a dificuldade enfrentada na resoluçáo de conflitos familiares que batem às portas do Poder Judiciário, em sua grande maioria envolvendo crianças e adolescentes, bem como o elevado número de processos que tramitam perante a justiça brasileira: mais de 70 milhóes, segundo dados do Conselho Nacional de Justiça (no ano de 2014) e, em média 10 (dez) anos para chegar ao fim?. Ao mesmo tempo, novas demandas chegam diariamente aos tribunais, favorecendo o aumento dos números na conta final.

No ano de 2014, 77.348 .718 processos tramitavam na justiça estadual brasileira. ${ }^{10}$ Tais números, além de indicarem que o Poder Judiciário brasileiro passa por difícil cenário, demonstram que é preciso inovar na forma de lidar com os processos judiciais no país.

9 CONSELHO NACIONAL DE JUSTIÇA. Justiça em números: publicado em janeiro de 2014. Disponível em:ftp://ftp.cnj.jus.br/Justica_em_Numeros/relatorio_jn2014.pdf. Acesso em: 27 abr. 2016.

10 CONSELHO NACIONAL DE JUSTIÇA. Justiça em números: publicado em janeiro de 2014. Disponível em:ftp://ftp.cnj.jus.br/Justica_em_Numeros/relatorio_jn2014.pdf. Acesso em: 27 abr. 2016. 
E todos aqueles que recorrem ao Poder Judiciário têm por objetivo a tutela jurídica de um interesse. As partes objetivam que a sua pretensão seja atendida de maneira imediata e que a resposta estatal lhe seja favorável.

De acordo com dados fornecidos pelo CEJUSC/PG, de junho a dezembro de 2015 foram designadas 335 (trezentos e trinta e cinco) audiências de conciliação com um total de 167 (centro e sessenta e sete) audiências conclusivas (consideradas aquelas que resultaram em acordo formalizado ou encaminhamento para instruçáo processual). Das 167 (cento e sessenta e sete) audiências conclusivas, 23\% (39 audiências) pelo menos uma das partes do processo participou das oficinas do Projeto de Extensão "Falando em Família"; e destas 39 (trinta e nove) audiências, 74\% dos processos resultaram em acordo homologado e $26 \%$ foram encaminhados para instrução processual.

Também quanto ao Projeto, durante o ano de 2015, no período de junho a dezembro, foram realizadas vinte e duas oficinas com a participação de 63 (sessenta e três) jurisdicionados. Além dos resultados percentuais obtidos, cabe destacar também as respostas dadas a duas perguntas constantes no questionário preenchido pelas partes ao final de cada oficina: a questáo de $\mathrm{n}^{\circ} 6$, que menciona "antes de participar da oficina, tinha conhecimento dos efeitos e consequências de um processo judicial?" e $\mathrm{n}^{\circ}$ 8: "Houve alguma mudança na sua forma de pensar após a participação na oficina (especialmente quanto ao processo)?”.

Do total de participantes das oficinas, cinquenta e seis (56) jurisdicionados responderam a essas perguntas, sendo que para a questão de número 6, trinta e sete (37) pessoas (66\%) disseram desconhecer os efeitos e consequências do processo judicial. Nesse contexto, sem o conhecimento de questóes como tempo estimado de duração de uma ação judicial ou sem o esclarecimento de questôes básicas, atinentes ao direito de alimentos e guarda, por exemplo, muitas das questóes levadas a juízo tenderiam a se complicar e a ser motivo de inúmeras discussóes ao longo do processo, as quais poderiam ser evitadas se esclarecidas previamente.

Verificou-se, ainda, que 47 pessoas (84\%) declararam terem modificado sua forma de pensar após a realização do trabalho nas oficinas, principalmente quanto às questôes relacionadas ao processo. Isso indica, que ao terem contato com a informaçáo, muitos assuntos que antes eram motivo de dúvida e discussão com a outra parte foram esclarecidos. Assim sendo, os efeitos dessa nova forma de pensar restam ilustrados no número de audiências 
com acordo formalizado (74\%) em que ao menos uma das partes participou das oficinas do projeto.

Em 2016 as atividades do projeto de extensão realizaram-se com a dinâmica inicialmente proposta e os percentuais mantiveram-se. Porém, novas medidas foram sendo implementadas para viabilizar o melhor desenvolvimento das atividades do Projeto de Extensão "Falando em Família", além do que, mediante convênio realizado com o conhecidíssimo Projeto Rondon, no mês de junho, foram levadas as oficinas para a Comarca de Palmeira-Pr, sempre fiéis aos mesmos princípios e finalidades do Projeto original.

\section{CONSIDERAÇÓES FINAIS}

A partir das informaçôes apresentadas é possível concluir que a prática institucional ora descrita vem alcançando seus objetivos ao longo de suas atividades. Isso porque a transmissão da informação e a solução de dúvidas possui grande importância na vida de cada indivíduo que procura o Poder Judiciário.

Após a solução de seus questionamentos e o melhor esmiuçar dos trâmites de um processo, as partes tornam-se mais propensas a estabelecer diálogo, o que antes não é viável por uma série de fatores e - conforme constatou-se no desenvolver do Projeto- principalmente, pela desinformação. Nesse sentido, cumpre destacar que a educação para a conciliação e a informação são capazes de não somente modificar as condiçôes pessoais do jurisdicionado, mas sua situação enquanto cidadão. Essa mudança torna-o capaz de problematizar fatos e buscar, por si só, as soluçôes adequadas e pertinentes para o seu conflito sem a necessidade de recorrer ao Estado-juiz para fazê-lo. Pela informação e esclarecimento há mais chances de alcançar o pleno exercício de suas potencialidades enquanto indivíduo ${ }^{11}$, dando-lhe o poder de conduzir o seu próprio destino.

Isto porque, ao permitir que a parte conheça seus direitos e ao orientá-la a exercê-los com base no diálogo consciente e respeitoso, permite-se que cada qual tome suas próprias decisóes em relação a sua demanda (e aos conflitos a ela correlatos). Quando isso acontece,

11 ANDREUCCI, A. C. P. T.; TEIXEIRA, C. N. Informação e educação para a cidadania: forças motrizes no empoderamento da mulher e concretização da igualdade de gênero no Brasil. Revista Direito Mackenzie. 
é possível falar em empoderamento da parte ${ }^{12}$, uma vez que a partir daí a decisão sobre os rumos de sua vida será fruto de decisóes tomadas em conjunto e de forma responsável pelos interessados. Também é por meio da informação e do esclarecimento há mais chances de alcançar o pleno exercício de suas potencialidades enquanto indivíduo. ${ }^{13}$ Desse modo, o jurisdicionado terá condiçóes de escolher o direcionamento de sua demanda, optando entre continuar com o seu tradicional andamento ou constituir acordo na audiência de conciliação, com o imprescindível acompanhamento do seu procurador.

Tal ocorre porque todos os membros do Projeto acreditam que somente o estabelecimento do diálogo é que permitirá que sejam atendidos os interesses de todos os envolvidos no conflito, minimizando os desgastes e abreviando o que poderia tornar-se uma longa batalha judicial.

O fato é que a prática ora descrita revela íntima relação com o bem estar da comunidade na qual se insere vez que com a sua implementaçáo, além do exercício da sua função social da Universidade, diversos indivíduos tiveram suas vidas modificadas e beneficiadas ao longo de quase dois anos de atuação. Essa percepção reforça o propósito inicial e estimula o constante aprimoramento das atividades, superando-se as dificuldades e se avançandose para novos desafios, sempre em prol do bem estar das famílias e, principalmente, de seus integrantes mais vulneráveis.

Desse modo, ainda que o atual cenário seja crítico e os desafios sejam grandes, com a abertura do Poder Judiciário, do Ministério Público, dos Núcleos de Prática Jurídica e da Defensoria pública para a implantaçáo de projetos como o ora descrito, bem como a colaboração dos profissionais atuantes nos sistemas de justiça, é possível acreditar na construção de um novo sistema para a solução dos conflitos em sociedade mais célere, efetivo e que garanta a todos, indistintamente, o acesso à Justiça e o exercício pleno de sua cidadania.

\section{REFERÊNCIAS}

12 ANDREUCCI, Ana Claudia Pompeu Torezan; TEIXEIRA, Carla Noura. Informação e educação para a cidadania: forças motrizes no empoderamento da mulher e concretizaçáo da igualdade de gênero no Brasil. Revista Direito Mackenzie.

13 PORTO, Bárbara Stephanie Calado; FASOLO, Thais da Silva. A informação como ferramenta para o empoderamento da população idosa. Cadernos da Escola de Educaçáo e Humanidades. 
ANDREUCCI, A. C. P. T.; TEIXEIRA, C. N. Informação e educação para a cidadania: forças motrizes no empoderamento da mulher e concretizaçāo da igualdade de gênero no Brasil. Revista Direito Mackenzie, v. 5, n. 1, p. 53-66.

ARRUDA ALVIM WAMBIER, T.; MENDES, A. G. de C. O novo código de processo civil brasileiro. Quarta, 16 de setembro de 2016. Dsponível em: < http://teste.wambier.com.br/ptbr/ artigos-br/o-novo-codigo-de-processo-civil-brasileiro> Acesso em: 01 jun. 2016.

CONSELHO NACIONAL DE JUSTIÇA. Justiça em números: publicado em janeiro de 2014. Disponível em:ftp://ftp.cnj.jus.br/Justica_em_Numeros/relatorio_jn2014.pdf. Acesso em: 27 abri. 2016.

CORREIA, Marcos Miranda. Trabalhando com jogos cooperativos. 5 ed. Sáo Paulo : Papirus, 2012

DIDIER JR, Fredie; Curso de direito processual civil: introduçáo ao direito processual civil, parte geral e processo de conhecimento I. - 17. ed. - Salvador: Jus Podivm, 2015. v. I.

GAMA, G. C, N.; GUERRA, L. S. Função social da família. In: GAMA, Guilherme Calmon Nogueira. Funçáo social no direito civil. 2. ed. São Paulo: Atlas, 2008.

GOULART, L. H. S.; PINTO, B. S. M. A autocomposiçáo sob a óptica do novo código de processo civil: o encaixe da mediaçáo e da conciliaçáo na nova sistemática processual. Revista Pós em Revista, edição 10, 25 de maio de 2015. Disponível em: < http://blog.newtonpaiva.br/ pos/e10-dir02-aautocomposicao-sob-a-optica-do-novo-codigo-de-processo-civil-o-encaixe-damediacao-e-daconciliacao-na-nova-sistematica-processual/> Acesso em: 01 jun. 2016.

PORTO, B. S. C.; FASOLO, T. da S. A informação como ferramenta para o empoderamento da populaçáo idosa. Cadernos da Escola de Educaçáo e Humanidades, Curitiba, vol. 01, n. 04, p. 52-57.

SCALQUETTE, A. C. S. Família e sucessões. 7 ed. São Paulo: Atlas, 2014.

VILLAÇA AZEVEDO, Á. Direito de família. São Paulo: Atlas, 2013. 